\title{
KOMUNIKASI MATEMATIK : PENYELESAIAN MASALAH DALAM PENGAJARAN DAN PEMBELAJARAN MATEMATIK
}

\author{
${ }^{1}$ Noor Akmar binti Azlan, ${ }^{2}$ Mohd Faizal Nizam Lee Abdullah \\ ${ }^{1,2}$ Fakulti Sains dan Matematik, \\ Universiti Pendidikan Sultan Idris
}

\begin{abstract}
Abstrak
Berdasarkan kepada kajian masalah matematik yang dibuat oleh Clements pada tahun 1970 dan 1983 di Pulau Pinang, didapati bahawa pelajar di Malaysia tidak menghadapi masalah mengira yang serius. Akan tetapi masalahnya yang sebenar adalah berkaitan dengan membaca, memahami dan membuat transformasi yang betul ketika menyelesaikan masalah matematik terutamanya yang melibatkan penyelesaian masalah matematik berayat. Komunikasi merupakan salah satu elemen yang penting dalam proses menyelesaikan masalah dalam pengajaran dan pembelajaran matematik. Pelajar berpeluang untuk terlibat dalam komunikasi secara matematik seperti membaca, menulis dan mendengar serta mempunyai dua keuntungan dari dua aspek yang berbeza iaitu berkomunkasi untuk belajar matematik dan belajar untuk berkomunikasi secara matematik. Kebanyakan pengkaji dalam bidang pendidikan matematik bersetuju, matematik boleh dan sekurang-kurangnya harus dipelajari melalui perbualan. Objektif utama kajian ini dijalankan adalah untuk mengkaji samada perbezaan aras soalan berdasarkan Taksonomi Bloom mempengaruhi tahap keaktifan komunikasi yang terbentuk antara pelajar dan guru di dalam bilik darjah. Dalam konteks kajian ini, pengkaji ingin melihat pada aras soalan manakah komunikasi berlaku dengan aktif dan sekiranya tidak berlaku apakah strategi yang sepatutnya diambil oleh guru untuk menggalakkan komunikasi berlaku. Kajian melibatkan satu kumpulan murid tingkatan 4 yang mempunyai masalah pembelajaran di sebuah sekolah menengah di daerah Seremban yang melaksanakan tugasan matematik yang disediakan. Kajian ini menggunakan pendekatan kualitatif, khususnya pemerhatian menggunakan rakaman video sebagai kaedah utama. Nota lapangan juga akan dicatat dan hasil kerja pelajar akan diambil kira bagi melengkapkan data video yang dirakam. Video data tersebut merupakan data primer bagi kajian ini. Analisis model Powell et al., (2013) akan digunakan untuk menganalisis video yang dirakam. Peristiwa penting dan kritikal sepanjang kajian ini akan diambil kira sepenuhnya. Seterusnya akan dianalisis untuk menguji hubungan antara komunikasi pelajar dan aras soalan yang terlibat. Bagi mendapatkan hasil kajian, suatu kerangka teoretikal yang berkaitan dengan komunikasi dan hirarki Taksonomi Bloom telah digunakan.
\end{abstract}

Kata kunci Komunikasi Matematik, Taksonomi Bloom, Penyelesaian Masalah, Analisis Wacana, Analisis Berfokus, Analisis Anak Panah, Peristiwa Kritikal, Produktif, Tidak Produktif. 


\begin{abstract}
Based on the study of mathematic problems created by Clements in 1970 and 1983 in Penang, it was found that students in Malaysia do not have a problem of serious thought. However, the real problem is related to read, understand and make the right transformation when solving mathematical problems, especially those involving mathematical word problem solving. Communication is one of the important elements in the process of solving problems that occur in the teaching and learning of mathematics. Students have the opportunities to engage in mathematic communication such as reading, writing and listening and at least have two advantages of two different aspects of communication which are to study mathematics and learn to communicate mathematically. Most researchers in the field of mathematics education agreed, mathematics should at least be studied through the mail conversation. The main objective of this study is the is to examine whether differences level of questions based on Bloom's Taxonomy affect the level of communication activity between students and teachers in the classroom. In this study, researchers wanted to see the level of questions which occur with active communication and if not occur what is the proper strategy should taken by teachers to promote the effective communication, engaging study a group of level 4 with learning disabilities at a secondary school in Seremban that perform mathematical tasks that are available. The study using a qualitative approach, in particular sign an observation using video as the primary method. Field notes will also be recorded and the results of student work will be taken into account to complete the data recorded video. Video data are primary data for this study. Analysis model by Powell et al., (2013) will was used to analyze recorded video. Milestones and critical during this study will be fully taken into account. There will be analyzed the relationship between communication of students and the level of questions involved. For the study, a theoretical framework values were related to communication and hierarchy of Bloom's Taxonomy was used.
\end{abstract}

Keywords $\quad$ Mathematics Communication, Bloom's Taxonomy, Solving Problems, Critical Events, Focal Analysis, Preoccupational Analysis, Productive, Non Priductive.

\title{
PENGENALAN
}

Matematik secara khususnya diketahui umum memainkan peranan yang penting dalam mencorak dan membentuk bagaimana seseorang individu berinteraksi dengan kehidupan sehariannya. Walau bagaimanapun sehingga ke hari ini, masih ramai pelajar yang menganggap bahawa matematik adalah sesuatu yang sukar dan sangat abstrak untuk dipelajari. Hal ini kerana halangan yang pelbagai dalam proses mempelajari dan memahami konsep matematik itu sendiri mengikut tahap dan kebolehan pelajar. Oleh itu dalam usaha untuk menghapuskan tanggapan negatif ini, teknik pengajaran dan pembelajaran yang bersesuaian dan berkesan perlu dikenal pasti agar ianya mampu mengubah pencapaian dan minat pelajar terhadap matematik (Kamaludin, 1996). 
Dalam dunia pendidikan hari ini, proses komunikasi antara guru dan pelajar serta pelajar dan pelajar merupakan aspek yang kritikal dalam pengajaran dan pembelajaran di sekolah. Aspek ini menjadi prasyarat kepada proses penyampaian ilmu yang berkesan. Asas kepada pembentukan ruang interaksi ini ialah pembinaan kemahiran berkomunikasi, memahami aspek fundamental ilmu komunikasi itu sendiri dan mengaplikasinya secara kreatif (Sabri Ahmad, 2006).

Selaras dengan itulah, dalam tahun kebelakangan ini, ramai penyelidik matematik yang mendakwa bahawa peranan bahasa dan interaksi sosial semakin meningkat kepentingannya terhadap proses pembelajaran dan pengajaran matematik (Forman \& van Oers, 1998; Hoyles \& Forman, 1995; Monaghan,1999; Sfard, 2000; Sfard \& Kieran, 2001; Barwell, Leung, Morgan \& Street, 2005). Penggunaan wacana di dalam bilik darjah ketika mempelajari matematik merupakan suatu domain utama kepada pembelajaran subjek ini. Sebagai contoh, bagaimana cara seseorang pelajar itu belajar untuk mewakilkan sesuatu, bercakap, berfikir, bersetuju mahupun sebaliknya.

Oleh itu, ramai pendidik dan pengkaji yang percaya bahawa komunikasi yang terbentuk dari bahasa matematik merupakan salah satu komponen yang sangat penting dalam pembelajaran matematik dan ia merupakan cara untuk berkongsi serta menjelaskan sesuatu masalah yang berkaitan matematik. Melalui proses komunikasi juga ia dapat membantu murid dalam menjana sesuatu idea yang bernas dan bermakna sekaligus dapat dikongsi secara umum (NCTM, 2000).

Selain itu, dengan mendengar buah fikiran, pendapat serta penjelasan murid lain, ia memberi peluang kepada murid itu sendiri untuk membina kefahaman mereka tentang sesuatu konsep. Komunikasi yang terbentuk di antara rakan sebaya dan guru-guru dapat membina kefahaman yang lebih mendalam tentang sesuatu konsep matematik. Apabila murid berfikir, bertindak balas, berbincang, menghuraikan sesuatu, menulis, membaca, mendengar dan mengkaji tentang konsep matematik, mereka sebenarnya memperoleh 2 manfaat yang berbeza iaitu murid berkomunikasi untuk belajar matematik dan mereka belajar untuk berkomunikasi secara matematik (NCTM, 2000).

Fokus utama kajian ini dijalankan adalah untuk melihat hubungan antara aras soalan berdasarkan hirarki Taksonomi Bloom dengan interaksi murid ketika menyelesaikan masalah matematik. Kajian ini dijalankan untuk menguji pada aras soalan manakah murid paling aktif berkomunikasi ketika menyelesaikan masalah. Ia melibatkan penggunaan analisis wacana yang bersesuaian dan dilaksanakan dalam aktiviti berkumpulan. Oleh itu, dalam kajian ini juga, penggunaan wacana matematik akan digunakan bagi melihat sejauh mana keberkesanannya terhadap komunikasi yang melibatkan matematik.

\section{KERANGKA TEORETIKAL}

Kerangka teoretikal yang dibina adalah untuk mengkaji dan menilai proses komunikasi yang terhasil antara murid dengan murid di dalam bilik darjah. Kajian ingin melihat hubungan yang terhasil daripada proses komunikasi ini dengan aktiviti penyelesaian masalah matematik murid ketika proses pembelajaran dan pengajaran. 
Selain itu, kesannya juga akan dilihat dalam aktiviti berkumpulan yang dilaksanakan dalam bilik darjah bagi menyelesaikan masalah matematik yang melibatkan aras yang berbeza seperti ysng terdapat dalam Hiraki Taksonomi Bloom.

Perbualan, perbincangan sesama murid menghasilkan banyak peluang untuk menghurai, membuat justifikasi dan berkongsi cara serta idea yang ada. Hasil dari hubungan ini murid boleh bertukar pandangan dan pendapat mereka tentang sesuatu perkara. Daya tanggapan setiap murid adalah berbeza mengikut tahap perkembangan kognitifnya di samping dari mana proses pembelajaran yang telah mereka lalui.

Mengikut Mansor (1984), semakin banyak persamaan dalam pengalaman dan pembelajaran antara kedua individu itu, maka semakin mudah proses komunikasi antara murid. Melalui pengalaman dan pembelajaran yang berbeza ini juga akan memudahkan proses pembelajaran antara mereka memandangkan murid lebih selesa bila bersama dengan rakan sebaya mereka. Oleh itu, guru kena memastikan perhubungan ini diatur dan disusun supaya murid mendapat manfaat dari proses komunikasi yang terbentuk. Aktiviti kumpulan perlu dititikberatkan supaya murid dapat menggunakan pengalaman mereka untuk membantu rakan mereka dalam proses pembelajaran.

Kerangka teoretikal yang dicadangkan untuk kajian ini adalah seperti dalam Rajah 1 di bawah :

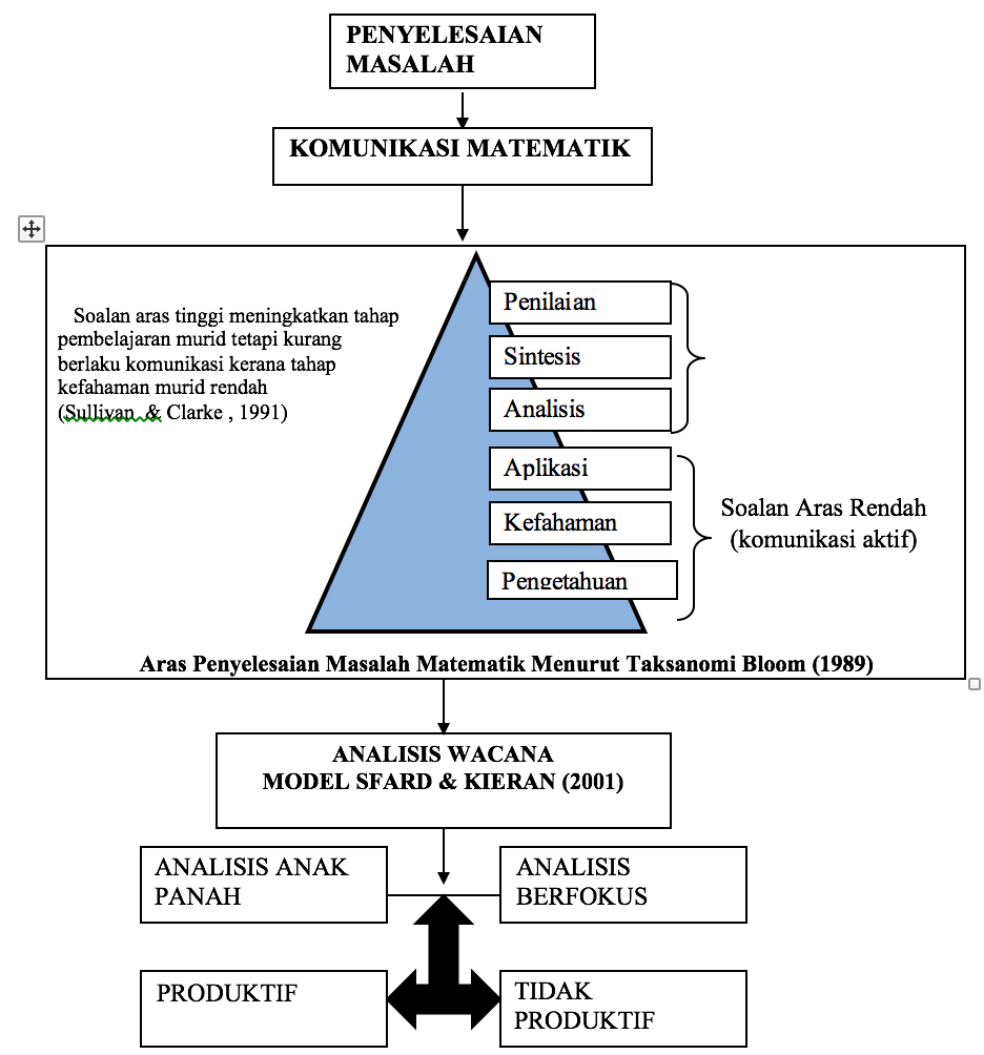

Rajah 1 Kerangka Teoretikal 


\section{METODOLOGI}

Kajian ini dijalankan untuk meninjau dan menilai interaksi yang terhasil antara murid apabila mereka bekerjasama dalam kumpulan untuk menyelesaikan tugasan matematik yang diberi oleh guru ketika sesi pembelajaran dan pengajaran di dalam kelas. Proses ini adalah untuk menilai aras soalan yang akan merangsang murid berkomunikasi paling aktif ketika menyelesaikan masalah matematik berayat. Aras soalan yang dibincangkan melibatkan hiraki Taksonomi Bloom. Kumpulan murid ini diuji secara berperingkat mengikut aras soalan yang ada. Kajian ini dirancang dalam dua fasa iaitu kajian rintis dan kajian utama. Kajian rintis telah dijalankan pada 12 Januari 2013 hingga 27 Januari 2013. Dapatan dari kajian rintis memberikan indikasi bahawa perlu dijalankan kajian utama. Justeru itu kajian utama telah dilaksanakan pada 8 Februari 2013 hingga 25 Mei 2013. Kajian ini melibatkan kajian yang berasaskan bilik darjah. Murid dipilih dengan menggunakan teknik persampelan bertujuan yang melibatkan unit atau kes yang 'berdasarkan kepada tujuan tertentu dan bukannya secara rawak' (Teddlie \& Yu, 2007). Tambahan pula, pemilihan sampel kajian bergantung kepada keupayaan murid untuk memberikan pendapat mereka ketika menyelesaikan masalah matematik, bergerak aktif dalam kumpulan serta dapat memberi kerjasama ke arah keberhasilan kajian ini.

Menurut Merriam (1998), 'Persampelan bertujuan ini adalah berdasarkan kepada andaian yang ingin dikaji, difahami dan untuk mendapatkan maklumat tertentu. Oleh itu, sampel hendaklah dipilih dari sumber yang paling mudah untuk dikaji.'

Kajian ini menggunakan pendekatan secara pemerhatian dengan menggunakan kaedah rakaman video sebagai kaedah utama. Hasil dari pemerhatian dan setiap jalan kerja yang dibuat oleh murid dicatat dan disimpan untuk melengkapkan data yang diperolehi dari rakaman video serta untuk mendapatkan pemerhatian yang lebih khusus terhadap pelaksanaaan pembelajaran yang sebenar. Hasil rakaman video dijadikan sumber utama dan Model Analisis oleh Powell (2003) telah digunakan.

\section{KAJIAN RINTIS}

Satu kajian rintis hendaklah dijalankan untuk menentukan ciri-ciri soalan yang perlu diubahsuai atau dikekalkan (Mohamad Najib, 1999). Kajian rintis dijalankan untuk menangani isu-isu yang terlibat sepanjang sesi rakaman video, instrumen kajian dan pemilihan murid sebagai sampel kajian di samping meninjau masalah yang akan timbul sebelum kajian sebenar dijalankan.

Kajian awal telah dilaksanakan di dalam kelas 4 Sains untuk menilai sejauh mana kesesuaian soalan yang diberikan untuk menguji komunikasi yang mungkin terhasil ketika murid menyelesaikan tugasan yang diberi oleh guru. Di samping itu, ia juga bertujuan untuk menguji tempoh masa yang diperuntukkan, sama ada ia bersesuaian dengan bilangan soalan yang perlu diselesaikan. Kajian rintis ini juga penting untuk menilai sejauh mana murid yang dipilih mampu untuk 
berkomunikasi dengan baik ketika menyelesaikan masalah di samping untuk memastikan instrumen mahupun peralatan kajian seperti soalan, kamera video dan tripod yang digunakan adalah bersesuaian dan mencukupi untuk kajian ini.

Seramai 16 orang daripada 24 orang telah dipilih untuk kajian ini. Ia berdasarkan kepada kriteria-kriteria yang telah ditetapkan, antaranya ialah tahap penguasaan topik murid yang baik serta kebolehan murid berkomunikasi dengan baik. Maklumat ini telah diperoleh daripada guru subjek tersebut melalui temubual pertama yang dijalankan.

Kajian rintis telah dijalankan sebanyak tiga kali dengan membuat penambahbaikan dari segi bentuk soalan yang disediakan. Pada rakaman pertama, hanya soalan subjektif digunakan manakala rakaman kedua ia hanya melibatkan soalan berbentuk objektif sahaja. Saya juga telah membuat penambahan peralatan iaitu alat perakam video kerana satu perakam sahaja tidak mencukupi untuk melihat proses komunikasi dan proses penyelesaian masalah yang dibuat oleh murid dalam kumpulan.

Namun begitu, hasil perbincangan dengan guru subjek, hanya empat orang murid sahaja yang dipilih. Mereka terdiri daripada murid yang mempunyai ciriciri yang lebih tinggi potensinya untuk menghasilkan data yang lebih berkualiti dan tepat. Murid tersebut merupakan murid yang paling aktif berkomunikasi dan mampu berkomunikasi mengikut aspek yang dikehendaki untuk kajian ini.

\section{INSTRUMEN KAJIAN}

Semasa kajian rintis dijalankan, dua perakam video, satu tripod, satu mini tripod dan cakera mini digunakan untuk merakam video buat kali pertama. Tujuan perakam video (V1) adalah untuk merakam aktiviti murid (separuh dari anggota badan). V1 diposisikan lebih kurang satu meter dari kedudukan murid dalam kumpulan. V1 diletakkan pada kedudukan yang tetap untuk memberi fokus utama kepada setiap tindak balas yang dihasilkan oleh murid.

Perakam video kedua (V2) digunakan adalah untuk merakam hasil kerja murid dalam kumpulan. Pada kali pertama rakaman dijalankan, murid menyelesaikan masalah di atas helaian masing-masing. Setiap hasil kerja murid perlu dirakam satu persatu. Malangnya, kaedah ini kurang bersesuaian untuk menentukan siapakah individu yang berkomunikasi ketika hasil kerja mereka dirakam. Tambahan pula, setiap murid menghasilkan jalan kerja yang berbezabeza untuk soalan yang sama. Ada juga yang menyelesaikan soalan yang lain terlebih dahulu tanpa mengikut urutan soalan.

Bagi menangani masalah ini, perbincangan telah diadakan semula dengan murid-murid tersebut bagi menerangkan semula bahawa kajian ini memerlukan kerjasama di antara ahli kumpulan. Mereka perlu menyelesaikan soalan secara berperingkat bersama-sama dan hanya seorang sahaja dari ahli kumpulan yang dibenarkan menyalin langkah kerja. Proses ini akan lebih mudah untuk mengenalpasti siapakah yang menyalin langkah kerja dan sekaligus dapat melatih murid agar menyelesaikan masalah secara berkumpulan. 


\section{PROSEDUR PENGUMPULAN DATA}

Kajian kualitatif melibatkan proses pengumpulan data yang berjalan serentak dengan proses menganalisis data. Proses ini melibatkan data yang mendalam serta dapat menjelaskan sesuatu masalah atau isu yang dikaji (Mack, Woodsong, MackQueen, Guest \& Namey, 2005). Ini adalah untuk mengelakkan pengkaji daripada berhadapan dengan masalah kehilangan beberapa maklumat penting.

Contohnya seperti temubual awal yang dilakukan dengan guru yang terlibat hendaklah ditranskripsikan dengan segera dan maklumat yang diperoleh dari perakam video hendaklah disokong dengan nota pemerhatian. Kemudian proses koding juga perlu dilakukan pada waktu tersebut.

Pelbagai pendekatan yang berbeza digunakan dalam kajian kualitatif antaranya ialah aktiviti pengumpulan data. Ia dapat dilakukan sama ada dengan memilih salah satu atau kesemua jenis sumber yang ada iaitu dokumen, pemerhatian dan temu bual (Meriam, 1998 ; Glesne \& Peshkin, 1992; Patton, 1990). Kajian ini telah menggunakan kesemua sumber yang ada tetapi lebih memberi penekanan kepada proses pemerhatian iaitu melalui rakaman video.

Kaedah rakaman video telah dipilih untuk mengumpulkan data kajian. Ia merupakan kaedah utama di samping menyalin nota pemerhatian. Pemerhatian dibuat berdasarkan kepada interaksi dan komunikasi murid yang terhasil ketika murid cuba menyelesaikan masalah matematik. Setiap hasil kerja murid dinilai dan segala maklumat penting telah direkodkan dan disimpan sebagai bukti penyelidikan.

\section{PROSES ANALISIS DATA}

Data yang diperoleh sepanjang kajian rintis memberikan banyak maklumat yang penting yang boleh digunakan untuk kajian sebenar. Data tersebut juga mengandungi maklumat komunikasi dan visual yang lengkap ketika murid melibatkan diri dalam aktiviti berkumpulan untuk menyelesaikan masalah matematik. Rakaman video menunjukkan interaksi yang jelas antara murid dalam kumpulan sekaligus membolehkan hasil kerja murid dinilai agar selari dengan apa yang dibincangkan sesama mereka.

Fokus utama rakaman video ini adalah untuk melihat interaksi murid dalam kumpulan. Melalui interaksi tersebut setiap wacana matematik yang digunakan antara murid dalam perbincangan tersebut dapat dikaji. Malah, apa yang lebih penting ialah kajian ingin melihat pada aras soalan manakah interaksi paling aktif berlaku.

Interaksi yang berlaku dinilai dan dianalisis dengan menggunakan kerangka kerja analisis wacana yang dihasilkan oleh Sfard dan Kieran (2001). Ini kerana kerangka kerja tersebut sangat relevan untuk menguji keberkesanan dan produktifnya interaksi yang terhasil antara murid.

Daripada proses analisis data yang dijalankan, terdapat tiga senario yang diperhatikan sepanjang proses rakaman video dijalankan. Senario pertama ialah semua murid bekerjasama dalam kumpulan dan berinteraksi secara positif antara satu sama lain untuk menyelesaikan tugasan. Senario kedua pula menunjukkan tidak semua murid mampu berkerja dalam kumpulan dengan baik, sebagai contoh ; jika terdapat empat murid, hanya dua atau tiga murid sahaja yang bekerjasama manakala yang lain 
hanya melihat dan mendengar. Manakala senario yang ketiga, menunjukkan muridmurid menyelesaikan tugasan secara individu.

Kajian menggunakan pendekatan yang diaplikasi oleh Sfard dan Kieran (2001) untuk menganalisis interaksi antara murid melalui analisis anak panah ( preoccupational analysis). Carta alir interaktiviti ini digunakan untuk memerhati interaksi antara murid samada ianya adalah komunikasi secara individu ataupun berkumpulan. Malah, apa yang lebih penting carta alir ini dugunakan untuk menentukan sama ada murid berinteraksi pada aras-objek (object-level) iaitu komunikasi secara matematik ataupun bukan-aras-objek (non-object-level) iaitu komunikasi bukan matematik.

Sebaliknya, apabila murid tidak berkomunikasi secara matematik (lisan), ini menunjukkan murid gagal untuk berinteraksi secara positif dalam gerak kerja kumpulan. Analisis selanjutnya adalah berdasarkan kepada rakaman video yang dijalankan sepanjang kajian utama dilaksanakan untuk mengkaji dan menilai samada interaksi yang terhasil akan membentuk satu wacana yang efektif dan produktif ataupun sebaliknya.

\section{DAPATAN KAJIAN SEBENAR}

Kajian sebenar dijalankan selama lebih kurang empat bulan, bermula Februari hingga Mei 2013. Sepanjang kajian ini dijalankan sebanyak 8 rakaman video telah dijalankan dengan mengambil masa lebih kurang 244 minit dan 29 saat. Ia melibatkan 6 topik tingkatan 4 yang berulang dengan soalan yang berbeza dan bab yang melibatkan tingkatan satu hingga tiga yang kesemuanya berjumlah 49 soalan. Setiap 8 set soalan yang dibentuk mengandungi aras soalan yang berbeza seperti yang terdapat dalam Taksonomi Bloom.

Setiap kategori dinilai mengikut darjah kesukaran masing-masing bermula dari yang paling mudah sehingga kepada yang lebih kompleks. Dalam erti kata lain, setiap murid perlu menguasai aras yang paling rendah sebelum mampu untuk menyelesaikan aras yang paling tinggi. Kategori tersebut terdiri daripada 6 peringkat utama iaitu pengetahuan, kefahaman, aplikasi, analisis, sintesis dan penilaian

Setelah proses mengkategori kesemua soalan mengikut aras lengkap, analisis data bagi video yang dirakam akan dijalankan dengan menggunakan Model Analisis Powell yang direka oleh Powell (2003). Model Analisis Powell ini mengandungi tujuh fasa bukan linear yang saling berinteraksi. Berikut adalah langkah-langkah bagaimana data dianalisis dengan menggunakan Model Powell.

\section{Fasa 1 : Menonton Keseluruhan Rakaman Video Penuh}

Model ini bermula dengan menonton semula rakaman video yang telah dibuat. Seperti yang dinyatakan sebelum ini oleh Powell (2003), pada peringkat ini hanya bahagianbahagian yang penting sahaja yang dinilai dan dikaji. Keseluruhan rakaman bagi setiap sesi yang dijalankan perlu ditonton. Ia mengambil masa $1-2$ jam untuk menonton dan mendengar secara intensif bagi memastikan segala isi kandungan video tersebut difahami sepenuhnya. Ia penting bagi mendapatkan data yang tepat. 


\section{Fasa 2 : Menterjemahkan Data Video}

Fasa kedua model ini akan menghuraikan dan menerangkan data video dengan lebih terperinci. Menurut Powell (2003):

Secara umumnya, untuk menilai isi kandungan yang ada dalam sesuatu video, seseorang pengkaji itu perlu membaca diskripsi (huraian) supaya mereka boleh mendapatkan objektif-objektif tertentu dalam video yang dirakam.

Tambahan pula, Powell (2003) menyatakan bahawa,

Diskripsi membantu pengkaji untuk lebih memahami dan arif tentang data yang diperoleh daripada menonton video yang dirakam berulang kali.

Selepas selesai fasa pertama, setiap jalan cerita yang ada dalam video dihuraikan dari awal hingga akhir. Huraian jalan cerita ini dibuat berdasarkan apa yang diperhatikan dan didengar sepanjang rakaman. Diskripsi video tersebut ditulis dalam bentuk pengkodan seperti yang ditunjukkan dalam contoh 2 Jadual 1. Kaedah ini membolehkan proses mengenalpasti episod atau peristiwa penting menjadi lebih mudah.

Kesemua nota pemerhatian dan hasil kerja murid digunakan untuk melengkapkan data dengan lebih sempurna. Nota pemerhatian dicatat dan direkodkan pada setiap sesi rakaman. Nota pemerhatian ini melibatkan topik dan subtopik yang diajar, objektif pembelajaran, contoh soalan dan situasi sebenar semasa sesi PdP berjalan.

Bagi menerangkan bagaimana proses pelaksanaan model analisis ini digunakan, satu contoh rakaman penuh yang telah dibuat dalam bentuk pengkodan ditunjukkan. Ia melibatkan topik Ungkapan dan Persamaan Kuadratik.

Jadual 1 Diskripsi Video

\begin{tabular}{|l|l|}
\hline Selang Masa & Penerangan (Video Transkrip) \\
\hline 00:00:00 & $\begin{array}{l}\text { Murid perlu menentukan sama ada ungkapan berikut merupakan } \\
\text { ungkapan kuadratik atau tidak. }\end{array}$ \\
$\begin{array}{l}\text { Farhana bertanya kepada rakan-rakan yang lain apakah dia ungkapan } \\
\text { kuadratik. Nalveen membalas ia tiada tanda 'sama dengan' (=). Farhana } \\
\text { bertanya apakah ciri-ciri lain dan kuasa tertinggi bagi pembolehubahnya } \\
\text { mesti dua. Fatini bersetuju dengan jawapan yang dinyatakan oleh }\end{array}$ \\
$\begin{array}{l}\text { Nalveen dan bertanya yang manakah jawapan yang bersesuaian. } \\
\text { Farhana mengatakan jawapannya adalah (b) sahaja. Fatini bertanya lagi } \\
\text { kenapa (a) dan (c) bukan ungkapan kuadratik. Farhana menjawab (a) } \\
\text { mempunyai kuasa tertinggi } x \text { adalah 1 manakala (c) pula mempunyai } \\
\text { lebih dari satu pembolehubah iaitu } p \text { dan } q .\end{array}$ \\
\hline
\end{tabular}




\begin{tabular}{|c|c|}
\hline $\begin{array}{l}00: 01: 36 \\
- \\
00: 03: 24\end{array}$ & $\begin{array}{l}\text { Murid perlu menukar persamaan kuadratik yang diberi dalam bentuk am. } \\
\text { Farhana menyatakan bentuk am persamaan kuadratik ialah } a x^{2}+b x+ \\
c=0 \text {. Nalveen mencadangkan agar persamaan dikembangkan terlebih } \\
\text { dahulu agar menjadi } 6 y-3 y^{2}=7 \text {. Kemudian Fatini bertanya adakah perlu } \\
\text { untuk memindahkan } 6 y-3 y^{2}=7 \text { ke sebelah kanan. Farhana membalas, } \\
\text { jawapannya adalah ya. Fatini menyatakan bahawa persamaan tersebut } \\
\text { perlu disamakan dengan } 0 \text {. Maka Farhana membuat kesimpulan bahawa } \\
\text { jawapannya adalah } 3 y^{2}-6 y+7=0 \text {. Bagi persamaan yang berikutnya, } \\
\text { Nalveen mencadangkan agar persamaan perlu dikembangkan seperti } \\
\text { biasa. Farhana menyatakan jawapannya adalah } x^{2}-6 x=9=2 x \text {. } \\
\text { Kemudian, Fatini bertanya, perlukah } 2 x \text { dipindahkan. Farhana menjawab } \\
\text { Ya. Seterusnya Nalveen menyatakan persamaan perlu disamakan dengan } \\
0 \text { dan hasilnya adalah } x^{2}-8 x=9=0 \text {. }\end{array}$ \\
\hline $\begin{array}{l}00: 03: 25 \\
- \\
00: 06: 30\end{array}$ & $\begin{array}{l}\text { Soalan No } 3 \text { memerlukan murid membentuk persamaan kaudratik dalam } \\
\text { sebutan p jika diberi tinggi, tapak dan luas segitiga. } \\
\text { Farhana memberikan idea supaya mereka membayangkan dan melukis } \\
\text { bentuk segitiga yang mana diberi tinggi dan tapaknya masing-masing } \\
\text { ialah } 4 p \text { dan } 2 p+1 \text {. (lukis segitiga) } \\
\text { Nalveen menyatakan bahawa luas segitiga tersebut ialah } 20 \mathrm{~cm}^{2} \text {. } \\
\text { Kemudian Fatini menambah lagi bahawa formula bagi luas segitiga } \\
\text { ialah } \frac{1}{2} \times \text { tapak } \times \text { tinggi. Fatini menyarankan supaya dimasukkan nilai } \\
\text { yang diberi ke dalam formula dan menghasilkan } 20=\frac{1}{2}(4 p)(2 p+1) \text {. } \\
\text { Kemudian Nalven menyatakan agar } 2 \text { dipindahkan ke sebelah kiri dan } \\
\text { didarabkan dengan } 20 \text {. Maka persamaan yang baru ialah } 40=4 p(2 p+ \\
\text { 1). Fatini menyatakan agar persamaan tersebut dikembangkan sehingga } \\
\text { menjadi } 8 p^{2}=4 p-40=0 \text {. }\end{array}$ \\
\hline $\begin{array}{l}\text { 00:06:31 } \\
- \\
00: 10: 41 \\
(*)\end{array}$ & $\begin{array}{l}\text { Nalveen menyatakan dalam bulan Februari Hafiz perlu mengumpul } y \\
\text { keping setem. Manakala, pada bulan Mac, dia perlu menambah lagi } \\
6 \text { keping setem. Farhana bertanya kenapa perlu ditambah. Nalveen } \\
\text { menjawab kerana Hafiz mengumpul } 6 \text { keping setem lebih dalam bulan } \\
\text { Mac. Fatini bersetuju dengan jawapan Nalveen. Seterusnya menyatakan } \\
\text { bahawa jumlah bilangan setem untuk } 2 \text { bulan tersebut ialah } y=y=6 \text {. } \\
\text { Maka, menghasilkan } 2 y+6 \text {. Nalveen menambah dengan mengatakan } \\
\text { bahawa kuasa } 2 \text { bagi jumlah bilangan setem yang dikumpul dalam } 2 \\
\text { bulan tersebut ialah } 576 \text {. Kemudian Fatini menyatakan persamaan yang } \\
\text { terhasil ialah }(2 y+6)^{2}=576 \text {. Mereka mengembangkan persamaan } \\
\text { tersebut sehingga menghasilkan } 4 y^{2}+24 y+36=576 \text {. Nalveen } \\
\text { mencelah, } 576 \text { perlu dipindahkan ke sebelah kiri. Maka, persamaan } \\
\text { yang terbentuk ialah } 4 y^{2}+24 y-540=0 \text {. Kemudian Fatini berkata } \\
\text { bahawa untuk mencari nilai } y \text {, mereka perlu memudahkan persamaan } \\
\text { terlebih dahulu dengan membahagikannya dengan } 4 \text {. Maka, ia dapat } y^{2} \\
+6 y-135=0 \text {. Kemudian Nalveen meminta agar persamaan tersebut } \\
\text { difaktorkan sehingga menghasilkan nilai } y \text { bersamaan dengan }-15 \text { dan } 9 \text {. } \\
\text { Maka, } 9 \text { dipilih. }\end{array}$ \\
\hline
\end{tabular}




\begin{tabular}{|c|c|}
\hline $\begin{array}{l}00: 10: 42 \\
- \\
00: 16: 20\end{array}$ & $\begin{array}{l}\text { Farhana mengandaikan pergerakan objek dari A ke B adalah berjarak } \\
21 \text { meter (sambil Zafirah melukis gambar rajah pergerakan tersebut). } \\
\text { Nalveen menyatakan masa yang diambil untuk sampai ke titik B ialah } x \\
+6 \text { minit. Seterusnya, Farhana menambah lagi dengan menyatakan laju } \\
\text { puratanya ialah } x-14 \text { mean }^{-1} \text {. Fatini bertanya apakah formula bagi } \\
\text { purata laju. Farhana membalas bahawa formula bagi laju adalah jarak } \\
\text { dibahagi dengan masa. Nalveen mencelah dengan menyatakan untuk } \\
\text { mencari masa, laju hendaklah dibahagikan dengan jarak. Maka, hasilnya } \\
x-14=\frac{21}{x+6} \text {. Nalveen meneruskan lagi dengan menyatakan bahawa } x+ \\
6 \text { perlu didarabkan dengan } x \text { - } 14 \text { sehingga menghasilkan } x^{2}-8 x-105= \\
0 \text {. Seterusnya persamaan untuk mencari nilai } x \text { persamaan tersebut perlu } \\
\text { difaktorkan. Fatini meyatakan nilai } x \text { yang diperoleh ialah } 15 \text { dan }-7 \text {. } \\
\text { Bagi mencari masa pergerakan objek yang bergerak dari A ke B, Farhana } \\
\text { menyatakan nilai } x \text { perlu digantikan ke dalam } x+6 \text {. Maka, Nalveen } \\
\text { menyatakan jawapannya adalah } 21 \text { minit. }\end{array}$ \\
\hline $\begin{array}{l}00: 16: 21 \\
- \\
00: 24: 35\end{array}$ & $\begin{array}{l}\text { Farhana menyatakan bahawa Siti menyimpan } \mathrm{RM}(\mathrm{s}+2) \text { pada setiap } \\
\text { bulan. Kemudian Nalveen menambah bahawa Siti menyimpan selama } \\
(2 \mathrm{~s}+1) \text { setiap bulan. Farhana berkata, untuk mengetahui jumlah } \\
\text { simpanan Siti, mereka perlu darabkan }(\mathrm{s}+2) \text { dengan }(2 s+1) \text {. Fatini } \\
\text { mencelah dengan mengatakan bahawa beliau yang akan menyelesaikan } \\
\text { persamaan tersebut. Maka jawapan yang diperolehi ialah } 2 \mathrm{~s}^{2}+5 \mathrm{~s}+2 \text {. } \\
\text { Nalveen kemudiannya menambah lagi dengan menyatakan bahawa Siti } \\
\text { menggunakan wang simpanannya untuk membeli beberapa buah buku } \\
\text { yang berharga RM (s }+6) \text {. Maka mereka perlu mengetahui berapakah } \\
\text { baki yang masih ada pada Siti. Manakala Fatini menjawab, mereka perlu } \\
\text { tolak } 2 \mathrm{~s}^{2}+5 \mathrm{~s}+2 \text { dengan }(\mathrm{s}+6) \text {. Maka ungkapan yang diperolehi oleh } \\
\text { mereka ialah } 2 \mathrm{~s}^{2}+5 \mathrm{~s}+2-\mathrm{s}-6 \text {. Apabila dipermudahkan, maka jawapan } \\
\text { akhir yang diperoleh ialah } 2 \mathrm{~s}^{2}+4 \mathrm{~s}-4 \text {. }\end{array}$ \\
\hline
\end{tabular}

\section{Fasa 3 : Mengenalpasti Peristiwa Yang Kritikal (critical events)}

Fasa seterusnya adalah untuk mengenalpasti peristiwa atau babak-babak yang kritikal yang terdapat di dalam rakaman yang telah ditonton. Peristiwa yang kritikal ini menunjukkan penglibatan wacana murid secara efektif dan produktif. Berdasarkan kepada Maher (2002), peristiwa yang kritikal adalah salah satu proses mengenalpasti masa-masa yang penting. Apabila pengkaji dapat mengenalpasti peristiwa kritikal yang boleh dikaitkan dengan persoalan kajian, simbol (*) ditandakan dan sedikit nota ringkas dicatatkan. Proses ini dapat membantu proses kajian dengan lebih mudah dan cepat.

Jadual 2 di bawah menunjukkan contoh peristiwa kritikal yang telah dikenalpasti yang dapat menjawab persoalan kajian. Ia menunjukkan bagaimana murid menyelesaikan tugasan dengan melibatkan aspek-aspek penting yang ingin dikaji seperti penggunaan wacana matematik dan komunikasi yang aktif terhasil bagi aras tersebut. 
Jadual 2 Peristiwa Kritikal

\begin{tabular}{|c|c|}
\hline Masa & Ulasan dan Transkrip Peristiwa yang Kritikal \\
\hline $\begin{array}{l}00: 06: 31 \\
- \\
00: 10: 41 \\
(*)\end{array}$ & $\begin{array}{l}\text { Peristiwa kritikal }(*) \text { yang dipilih melibatkan interaksi murid dalam } \\
\text { membentuk wacana matematik ketika menyelesaikan soalan yang } \\
\text { berikut. } \\
\text { [1] Farhana : Pada bulan Februari, Hafiz mengumpul sebanyak y } \\
\text { keping setem. Pada bulan Mac, Hafiz menambah lagi lebih } 6 \text { keping } \\
\text { setem. } \\
\text { [2] Nalveen : Kenapa perlu ditambah? } \\
\text { [3] Farhana : Ini kerana, hafiz mengumpul } 6 \text { keping setem lebih } \\
\text { daripada bulan Februari. } \\
\text { [4] Fatini : Ok. Kalau begitu jumlah bilangan setem untuk } 2 \\
\text { bulan ialah y }+y+6 \text {. Maka akan terhasil } 2 y+6 \text {. } \\
\text { [5] Nalveen : Soalan beri kuasa dua daripada jumlah bilangan } \\
\text { setem untuk } 2 \text { bulan ialah } 576 \text {. } \\
\text { [6] Fatini : Kita dapat bentukkan persamaan kuadratik seperti } \\
\text { berikut }(2 y+6)^{2}=576 \\
\text { [7] Farhana : Kemudian kembangkan }(2 y+6)^{2} \text { untuk menghasilkan } \\
\text { persamaan kuadratik yang baru seperti } 4 y^{2}+24 y+36=576 \text {. } \\
\text { [8] Nalveen : Pindahkan } 576 \text { ke sebelah kiri, maka persamaan } \\
\text { kuadratik yang baru ialah } 4 y^{2}+24 y-540= \\
\text { [9] Fatini : Untuk mencari nilai y, kita permudahkan persamaan } \\
\text { kuadratik dengan bahagikan dengan } 4 \text {, maka persamaan kuadratik } \\
\text { baru yang terhasil ialah } y^{2}+6 y-135=0 \text {. } \\
\text { [10] Nalveen : Kemudian faktorkan }(y+15)(y+9)=0 \text {. } \\
\text { Maka akan dapat nilai y ialah }-15 \text { dan } 9 \text {. Jadi kita pilih nilai yang } \\
\text { positif iaitu 9. }\end{array}$ \\
\hline
\end{tabular}

\section{Fasa 4 : Transkripsi audio atau video yang dirakam}

Seperti yang ditunjukkan dalam Jadual 2 di atas, proses transkripsi atau menyalin semula dialog yang terhasil antara murid semasa menyelesaikan tugasan matematik merupakan satu fasa yang penting bagi kajian. Ia kerana proses ini digunakan untuk menganalisis wacana matematik yang terbentuk ketika murid berkomunikasi menyelesaikan tugasan. Tambahan lagi, ia boleh digunakan sebagai bahan bukti dalam laporan penyelidikan yang dibuat (Powell, 2003). Semua rakaman yang dibuat akan menjalani proses yang sama.

\section{Fasa 5 : Pengkodan}

Pada peringkat ini, pengkodan merupakan satu proses penting di mana ia menentukan keberhasilan sesuatu kajian yang dibuat. Berdasarkan kepada Powell et al., (2003) :

Sama ada transkrip data dibuat atau sebaliknya, pengkodan tetap perlu dilaksanakan untuk menganalisis data video. Proses ini bertujuan untuk mengenalpasti tema bagi membantu pengkaji untuk mentafsir data.

Kesemua peristiwa kritikal akan dikodkan dengan menggunakan satu kerangka komunikasi matematik. Peristiwa kritikal ini dianalisis untuk mengenalpasti analisis 
wacana yang terhasil (Sfard dan Kieran, 2001). Model analisis wacana oleh Sfard \& Kieran ini mengandungi analisis berfokus (focal analysis) dan analisis anak panah (preoccupational analysis).

Pengkaji menggunakan analisis berfokus untuk menentukan keberkesanan wacana yang terhasil. Semua peristiwa kritikal akan dikodkan dengan melibatkan tiga komponen tumpuan iaitu fokus perkataan (pronounced focus), fokus perhatian(attended focus) dan fokus tujuan (intendedfocus).

Jadual 3 Analisis Tumpuan Tiga Pihak Rakaman 4

\begin{tabular}{|c|c|c|c|c|c|}
\hline \multicolumn{3}{|l|}{ Farhana } & \multicolumn{3}{|l|}{ Nalveen } \\
\hline Fokus Perkataan & $\begin{array}{l}\text { Fokus } \\
\text { Perhatian }\end{array}$ & $\begin{array}{l}\text { Fokus } \\
\text { Tujuan }\end{array}$ & $\begin{array}{l}\text { Fokus } \\
\text { Perkataan }\end{array}$ & $\begin{array}{l}\text { Fokus } \\
\text { Perhatian }\end{array}$ & $\begin{array}{l}\text { Fokus } \\
\text { Tujuan }\end{array}$ \\
\hline \begin{tabular}{|l} 
[3] Hafiz \\
mengumpul \\
6 keping \\
setem lebih \\
daripada \\
bulan \\
Februari.
\end{tabular} & $2 y+6$ & $\begin{array}{l}\text { Jumlah } \\
\text { bilangan } \\
\text { setem }\end{array}$ & $\begin{array}{l}\text { [2] Kenapa } \\
\text { perlu } \\
\text { ditambah } \\
\text { dengan } 6\end{array}$ & $2 y+6$ & $\begin{array}{l}\text { Jumlah } \\
\text { bilangan } \\
\text { setem }\end{array}$ \\
\hline $\begin{array}{l}\text { [7] Kembangkan } \\
(2 y+6)^{2}\end{array}$ & $\begin{array}{l}a x^{2}+b x+c \\
=0\end{array}$ & $\begin{array}{l}\text { Bentuk am } \\
\text { kuadratik }\end{array}$ & $\begin{array}{l}\text { [8]Persamaan } \\
\text { kuadratik } \\
\text { yang baru } \\
\text { ialah } 4 y^{2}+ \\
24 y-540 \\
\quad=0\end{array}$ & $\begin{array}{l}a x^{2}+b x+ \\
c=0\end{array}$ & $\begin{array}{l}\text { Bentuk } \\
\text { am } \\
\text { kuadratik }\end{array}$ \\
\hline
\end{tabular}

\begin{tabular}{|l|l|l|}
\hline Farhana & Fokus Perhatian & $\begin{array}{l}\text { Fokus } \\
\text { Tujuan }\end{array}$ \\
\hline $\begin{array}{l}\text { [4] Kalau begitu jumlah bilangan setem } \\
\text { untuk 2 bulan ialah } y+y+6 . \text { Maka } \\
\text { akan terhasil } 2 y+6 .\end{array}$ & $2 y+6$ & Jumlah bilangan setem \\
$\begin{array}{c}\text { [6] Bentukkan persamaan kuadratik } \\
\text { seperti berikut }(2 y+6)^{2}=576 .\end{array}$ & $a x^{2}+b x+c=0$ & Bentuk am kuadratik \\
\hline
\end{tabular}

Seterusnya, untuk analisis anak panah (preoccupational analysis), pengkaji menggunakan carta aliran interaktiviti oleh Sfard dan Kieran (2001) untuk menganalisis interaksi antara murid. 


\section{$\begin{array}{lll}\text { Farhana } & \text { Nalveen } & \text { Fatini }\end{array}$}

[1]

[2]

[3]

[4]

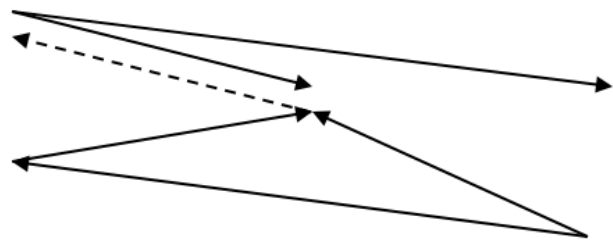

[5]

[6]

[7]

[8]

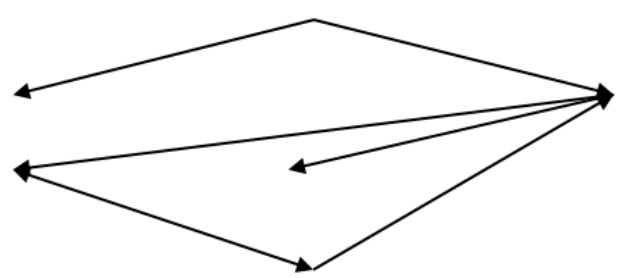

[9]

[10]

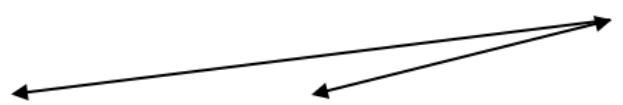

Rajah 2 Carta Aliran Interaktif Soalan 4 (Rakaman 4)

\section{Fasa 6 : Membina Jalan Cerita}

Menurut Powell et al.,(2003) :

'Jalan cerita merupakan keputusan yang terhasil daripada data yang diperoleh dengan memberi perhatian yang khusus untuk mengenalpasti kod-kod tertentu'.

Tambahan pula, mereka berpendapat bahawa :

Membina jalan cerita bagi keseluruhan rakaman yang dibuat memerlukan pengkaji menyediakan matlamat yang kukuh dan padat bagi setiap peristiwa kritikal yang diperhatikan.

\section{Fasa 7 : Mengarang Keseluruhan Kajian}

Powell (2003) menyatakan :

'Dalam membina jalan cerita ia bermula dari awal kajian dan dicatatkan dalam satu laporan penyelidikan, di mana pengkaji menggariskan teoretikal mereka secara berat sebelah'.

Manakala Erickson (1992) menyatakan :

Mereka akan menghuraikan keseluruhan cerita kepada bahagian-bahagian yang lebih ringkas, mentafsir bahagian-bahagian tersebut berdasarkan keseluruhan cerita dan menghuraikannya semula jalan cerita tersebut. Seterusnya mengkaji tafsiran tertentu yang terdapat di dalam jalan cerita dengan menggunakan data yang diperoleh sebagai bahan bukti kepada kajian yang dibuat. Sekaligus membentuk satu naratif ataupun karangan bertulis (m.s 431, Powell et al., 2003). 


\section{RUMUSAN KAJIAN}

Dapatan kajian menunjukkan ketika murid menyelesaikan tugasan matematik yang diberi, mereka akan berkomunikasi secara matematik ataupun sebaliknya. Terdapat tiga kategori yang melibatkan penggunaan wacana secara matematik iaitu:

1. Penglibatan sepenuhnya wacana matematik secara efektif dan produktif.

2. Tiada penglibatan wacana matematik secara efektif dan produktif.

Bagi kategori 1, murid didapati berinterksi secara matematik keseluruhannya. Pada peringkat ini, wacana yang dihasilkan adalah efektif dan produktif. Ini disokong lagi dengan kejayaan murid menyelesaikan tugasan yang bersesuaian dalam kajian ini. Terdapat 10 soalan daripada 49 soalan keseluruhannya yang berkaitan seperti yang telah dijelaskan dalam bab 5.

Sepanjang proses penyelesaian 10 soalan ini berlaku, murid didapati berinteraksi dan mempunyai fokus yang sama untuk membentuk satu wacana matematik yang efektif. Interaksi antara murid telah menghasilkan satu segitiga tertutup yang mana ia menunjukkan wacana yang terbentuk adalah produktif. Berdasarkan kepada sudut pandangan wacana matematik, murid berinterkasi melalui tiga komponen utama iaitu, konsep matematik, ciri-ciri komunikasi yang terbentuk dan syarat-syarat komunikasi itu dinilai. Sebagai contoh, semua soalan yang berjaya dibincangkan oleh murid menunjukkan mereka berkongsi maklumat atau fokus yang sama untuk mencari penyelesaian.

Bagi kategori 2 pula merupakan soalan matematik yang tidak menghasilkan sebarang wacana matematik dalam interaksi antara murid-murid. Terdapat 39 soalan yang gagal menghasilkan wacana yang efektif dan produktif. Kesemua soalan tersebut merupakan soalan aras rendah seperti soalan pengetahuan dan pemahaman. Murid tidak memerlukan perbincangan yang serius tetapi cukup sekadar mengimbas pembelajaran lepas untuk mendapatkan penyelesaian.

Keseluruhan 39 soalan tersebut berjaya diselesaikan dengan betul sekalipun tiada interaksi secara matematik dibentuk. Murid tidak perlu berbincang ataupun menetapkan matlamat untuk menyelesaikan soalan. Apatah lagi untuk mengeluarkan idea-idea yang bernas untuk mendapatkan jawapan. Hasilnya, interaksi mereka gagal untuk membentuk satu segitiga tertutup untuk mendapatkan satu wacana yang efektif dan produktif.

\section{RUJUKAN}

Aziz Omar, Sabri Ahmad \& Tengku Zawawi Tengku Zainal (2006). Isu-isu dalam pendidikan matematik. Kuala Lumpur. Utusan Publications dan Distributions Sdn Bhd.

Clements, M. A. (1999). Language aspects of mathematical modelling in primary school. Proceedings of the Fourth Annual Conference of the Department of Science and Mathematics Education. Gadong: ETC Universiti Brunei Darussalam. 
Kamaludin Ahmad (1996). Modul Pengajaran Matematik Sekolah Rendah : Pengajaran Pemusatan Murid Dan Berasaskan Konstruktivisme. Maktab Perguruan Mohd Khalid, Johor Bharu.

Mansor Ahmad Saman, Razali Mohamad \& Shawaludin Anis (1995). Pengantar komunikasi. Penerbit USM. Pengajian Ilmu Kemanusian.

Mack, N., Woodsong, C., Macqueen, KM., Guest, G., \& Namey, E., (2005). Qualitative Research Methods: A Data Collector's Field Guide. Research Triangle Park, NC: Family Health International.

Mohamad Najib Abdul Ghafar (1999). Penyelidikan Pendidikan. Skudai: Penerbitan Universiti Teknologi Malaysia.

National Council of Teachers of Mathematics. (2000). Principles and standards for school mathematics. Reston, VA: NCTM

Powell, A. B., Francisco, J. M., and Maher, C. A. (2003). An analytical model for studying the development of learners' mathematical ideas and reasoning using videotape data. Journal of Mathematical Behavior, 22(4), 405 - 435.

Sfard, A. (2001). There is more to discourse than meets the ears: looking at thinking as communication to learn more about mathematical learning. Educational Studies in Mathematics, 46(1-3), $13-57$.

Sfard, A. (2008). Thinking as communicating: Human development, the growth of discourses, and mathematizing. New York: Cambridge University Press.

Sfard, A., and Kieran, C. (2001). Cognition as communication: rethinking learningby-talking through multi-faceted analysis of students' mathematical interactions. Mind, Culture, and Activity, 8(1), 42 - 76. 